\title{
Salvaging a malpositioned fully covered self-expanding metal stent for pancreatic fluid collection drainage
}

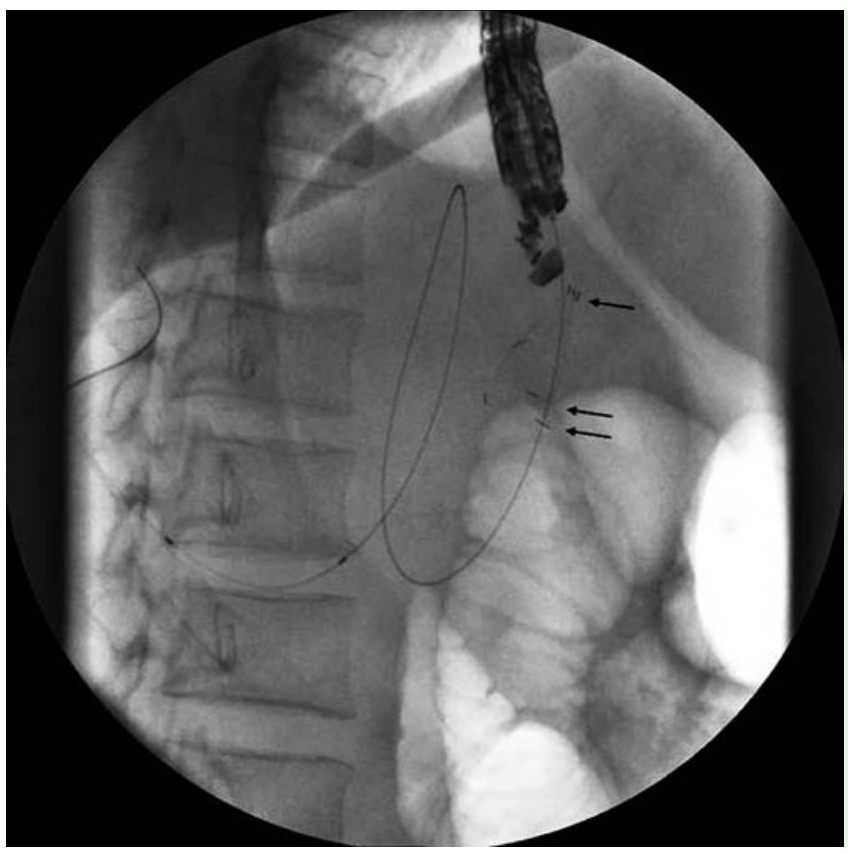

Fig. 1 Radiographic image showing the selfexpanding metal stent (SEMS) that was misplaced at deployment. The proximal (gastric end; single arrow) of the SEMS is nonexpanded and within the cyst wall; the distal end of the SEMS is opened within the area of walled-off necrosis (WON; double arrow). The guidewire is seen still passing through the SEMS.

A 44-year-old man presented with a large, symptomatic pancreatic fluid collection (PFC) 6 weeks after an episode of alcoholrelated acute necrotizing pancreatitis. Imaging confirmed an area of walled-off necrosis (WON) measuring $15 \times 12 \mathrm{~mm}$ and containing solid debris.

He underwent endoscopic ultrasound (EUS)-guided drainage with the aim of placing a dedicated fully covered self-expanding metal stent (SEMS; Nagi stent, Taewoong Medical, Seoul, South Korea) of $16 \mathrm{~mm}$ in diameter and $20 \mathrm{~mm}$ in length. The initial steps of the drainage procedure via the stomach (needle puncture, creation of a cystogastric fistula using a coaxial over-the-wire 6-Fr cystotome, and smallcaliber balloon dilation) were uneventful. During deployment of the SEMS, the distal end opened appropriately inside the WON (confirmed on EUS and fluoroscopy); however, at the point of final SEMS release, there was an excessive gush of turbid, purulent fluid into the stomach, which obscured the endoscopic visualization of the SEMS (within the delivery catheter) and its yellow marker (which indicates the proximal end of the SEMS). After its release, the proximal (gastric end) of the SEMS was noted to be within the cyst wall. The guidewire was still in position passing through the stent ( $\bullet$ Fig. 1). This untoward event was immediately identified, but unfortunately efforts to reposition the SEMS failed. A 6-Fr nasocystic catheter was therefore placed over the guidewire to drain the collection. There were no post-procedure adverse events.

After 48 hours, a gastroscope (Olympus; diameter $9.2 \mathrm{~mm}$ ) was passed over the nasocystic catheter keeping the guidewire, which had been re-routed through the oral cavity, inside. The fistulous opening was dilated with $12-\mathrm{mm}$ controlled radial expansion (CRE) balloon (Boston Scientific, Natick, Massachusetts, USA). On entering the cavity, the internally migrated Nagi stent was caught at its proximal edge with rat-tooth forceps and gently pulled back and repositioned in the desired place ( Video 1 ). The patient remained asymptomatic until his discharge. At 6 weeks, after resolution of the WON, the Nagi SEMS was removed.

Technical success rates are generally high when placing a dedicated SEMS for EUSguided drainage of PFCs [1-4]. A SEMS that is misplaced inside the PFC poses a challenge in terms of repositioning and may require either its removal or placement of a plastic stent through it. An inappropriately placed SEMS in a PFC can be

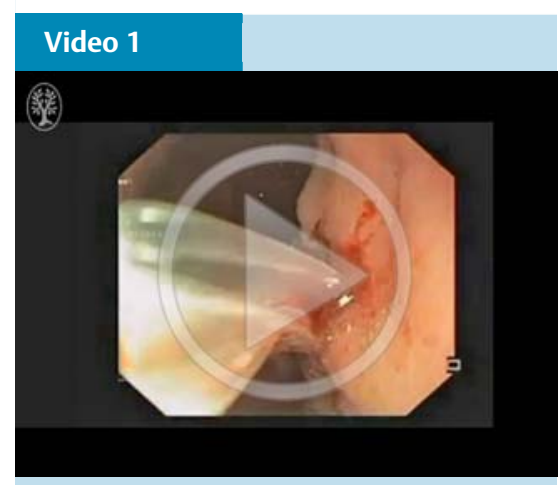

Endoscopic view showing the fistulous opening being balloon dilated and the internally migrated Nagi stent being caught at its proximal edge with rat-tooth forceps and gently pulled back and repositioned in the desired place.

salvaged with repositioning and reuse of same stent provided the guidewire is in place.

Endoscopy_UCTN_Code_CPL_1AK_2AG

Competing interests: None

\section{Sundeep Lakhtakia, Jahangeer Basha, Zaheer Nabi, Mohan Ramchandani, D. Nageshwar Reddy}

Asian Institute of Gastroenterology, Hyderabad, India

\section{References}

1 Walter $D$, Will $U$, Sanchez-Yague A et al. A novel lumen-apposing metal stent for endoscopic ultrasound-guided drainage of pancreatic fluid collections: a prospective cohort study. Endoscopy 2015; 47: 63-67

2 Siddiqui AA, Adler DG, Nieto J et al. EUS-guided drainage of peripancreatic fluid collections and necrosis by using a novel lumenapposing stent: a large retrospective, multicenter U. S. experience (with videos). Gastrointest Endosc 2016; 83: 699-707

3 Chandran S, Efthymiou M, Kaffes $A$ et al. Management of pancreatic collections with a novel endoscopically placed fully covered self-expandable metal stent: a national experience (with videos). Gastrointest Endosc 2015; 81: $127-135$ 
4 Rinninella E, Kunda R, Dollhopf $M$ et al. EUSguided drainage of pancreatic fluid collections using a novel lumen-apposing metal stent on an electrocautery-enhanced delivery system: a large retrospective study (with video). Gastrointest Endosc 2015; 82: $1039-1046$

\section{Bibliography}

Dol http://dx.doi.org/

10.1055/s-0042-106966

Endoscopy 2016; 48: E180-E181

(c) Georg Thieme Verlag KG

Stuttgart · New York

ISSN 0013-726X
Corresponding author

Sundeep Lakhtakia, MD, DM

Asian Institute of Gastroenterology Hyderabad

Telangana 500082

India

Fax: +91-40-23324255

drsundeeplakhtakia@gmail.com 